\title{
Needle-Free and Needle-Based Growth Hormone Therapy in Children: A Pooled Analysis of Three Long-Term Observational Studies
}

\author{
Tilman R. Rohrer ${ }^{a}$ Sabine Ceplis-Kastner ${ }^{b}$ Norbert Jorch ${ }^{c}$ Hermann L. Müller ${ }^{d}$ \\ Roland Pfäffle ${ }^{e}$ Thomas Reinehr ${ }^{f}$ Annette Richter-Unruhg \\ Claudia Weißenbacher ${ }^{\mathrm{h}}$ Paul-Martin Holterhus ${ }^{\mathrm{i}}$ \\ a Department of Paediatrics, Saarland University Medical Centre, Homburg/Saar, Germany; ${ }^{b}$ Medical Department, \\ Ferring Arzneimittel GmbH, Kiel, Germany; 'Protestant Hospital of the Bethel Foundation, Children's Hospital, \\ Bielefeld, Germany; ${ }^{d}$ Department of Paediatrics and Paediatric Haematology/Oncology, University Children's \\ Hospital, Klinikum Oldenburg AöR, Oldenburg, Germany; ${ }^{e}$ Department of Paediatric Endocrinology, Children's

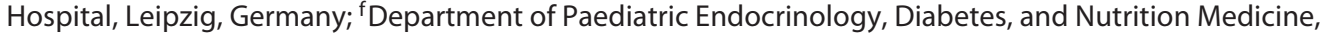 \\ Vestische Kinder- und Jugendklinik, University of Witten/Herdecke, Datteln, Germany; ${ }^{9}$ Department of Paediatric \\ Endocrinology and Diabetology, University Children's Hospital, Ruhr University Bochum, Bochum, Germany; \\ h Department of Endocrinology, Dr. von Haunersches Children's Hospital, LMU Munich, Munich, Germany; ${ }^{\text {i Division }}$ \\ of Paediatric Endocrinology and Diabetes, Christian-Albrechts University of Kiel (CAU) and University Hospital \\ Schleswig-Holstein (UKSH), Campus Kiel, Kiel, Germany
}

\section{Keywords}

Growth hormone deficiency · Turner syndrome .

Somatropin · Jet delivery · Auxological outcome

\begin{abstract}
Background: Treatment with growth hormone $(\mathrm{GH})$ is standard clinical practice in children with GH deficiency (GHD) or Turner syndrome (TS). Hitherto, no long-term data on auxological outcome and safety of Zomacton ${ }^{\circledR}$ have been published. Data comparing needle-free administration (NF) and needle injection (NI) of GH are very sparse. Aims: To analyse longitudinal auxological outcome and safety data of $\mathrm{GH}$ treatment-naïve patients diagnosed with GHD or TS and to compare NF and NI in a real-life setting. Methods: Pooled auxological data and safety information from three consecutive prospective observational Zomacton ${ }^{\circledR}$ studies covering 22 years of treatment were analysed and NF was compared to NI. Results: The safety cohort comprised 1,595 patients
\end{abstract}

\begin{tabular}{ll}
\hline KARGER & $\begin{array}{l}\text { Co } 2019 \text { The Author(s) } \\
\text { Published by S. Karger AG, Basel }\end{array}$ \\
E-Mail karger@karger.com & $\begin{array}{l}\text { This article is licensed under the Creative Commons Attribution- } \\
\text { NonCommercial-NoDerivatives 4.0 International License (CC BY- } \\
\text { NC-ND) (http://www.karger.com/Services/OpenAccessLicense). } \\
\text { Nsage and distribution for commercial purposes as well as any dis- } \\
\text { tribution of modified material requires written permission. }\end{array}$
\end{tabular}

who received at least one $\mathrm{GH}$ dose. The auxological outcome cohort comprised 856 treatment-naïve patients with followup data $\geq 12$ months. Height-SDS and height velocity improved significantly during the first 3 years of treatment. Documented choice of device was available for 658 patients (NF 69.1\%, NI 30.9\%). NF administration was non-inferior to NI. No previously unknown safety signals occurred. Conclusion: Real-life data show that treatment with Zomacton ${ }^{\circledR}$ improves auxological outcome parameters without new safety concerns. NF administration of $\mathrm{GH}$ represents a useful alternative to $\mathrm{NI}$ in children with growth disorders.

$$
\begin{aligned}
& \text { () } 2019 \text { The Author(s) } \\
& \text { Published by S. Karger AG, Basel }
\end{aligned}
$$

\section{Introduction}

Recombinant human growth hormone $(\mathrm{GH})$ treatment has become standard clinical practice in children with GH deficiency (GHD) over the last decades. The 
main objective of GH therapy is to optimise growth during childhood and adolescence with the aim of achieving an adult height within the population-specific normal ranges [1]. Over the last 30 years, several products have been approved for the treatment of GHD and other growth disorders such as Turner syndrome (TS), and have been proven to be effective [2] as well as generally safe [3].

Treatment with GH involves daily injections, which may entail low therapy adherence and persistence due to needle anxiety or injection pain [4]. Zomacton ${ }^{\circledR}$ (somatropin; Ferring Pharmaceuticals), which has been approved for the treatment of GHD since 1992 and for TS since 2001, can be injected using a needle-free (NF) transjection device. Persistence with GH therapy has been shown to be significantly longer in patients using NF compared to needle-based injection (NI) devices [4]. However, it has not been investigated whether there are differences between the groups regarding treatment outcome and safety. In general, long-term data on Zomacton ${ }^{\circledR}$ have not been reported before. In particular, data on transjected GH are very sparse.

To obtain data from a real-life setting, a pooled analysis was performed of the data from three hitherto unpublished, prospective observational studies, consecutively conducted over a 22 -year period. The main objectives of the analysis were to examine the auxological outcomes including height, height velocity (HV), and their standard deviation scores (SDS) after 12, 24, and 36 months of therapy as well as the safety of Zomacton ${ }^{\circledR}$ treatment in a group of GH treatment-naïve paediatric patients diagnosed with GHD or TS, and to compare these parameters between patients using the NF or NI devices.

During the 22-year time period of data acquisition, changes were made to the German diagnostic guidelines for GHD [5]. One significant change was the introduction of sex steroid priming at the end of 2008. Generally, GH secretion is low in early puberty, making it difficult sometimes to differentiate GHD from constitutional delay of growth and puberty (CDGP) [6]. Administration of sex steroids prior to $\mathrm{GH}$ stimulation tests is thought to improve the specificity of diagnosis and reduce false-positive diagnoses. Since November 2008, therefore, the German diagnostic guidelines on GHD have recommended priming with sex steroids before GH tests in prepubertal boys $\geq 10$ years and prepubertal girls $\geq 8$ years of age. The present analysis thus also aimed to determine whether this guideline recommendation had an influence on diagnosis and treatment decisions.

\section{Materials and Methods}

\section{Study Design and Treatment}

Data of patients from three hitherto unpublished, consecutive Zomacton ${ }^{\circledR}$ observational studies were evaluated in a pooled analysis. Data acquisition was conducted at 71 children's hospitals and specialist endocrinology clinics as well as private practices in Germany between December 1994 and July 2016. Prior to study initiation, approval was obtained from the ethics committee of the medical faculty of Christian-Albrechts University (CAU), Kiel, Germany. The studies were conducted in accordance with Section 67 (6) of the Medicinal Products Act (AMG). Public disclosure took place under ClinicalTrials.gov ID No. NCT01365351. Patients enrolled in the studies were infants, children, and adolescents receiving treatment with Zomacton ${ }^{\circledR}$ who had written informed consent provided by their parents or legal guardians and were either GH-naïve or already being treated with GH at study entry.

The three observational multi-centre studies aimed to collect data on treatment outcome and safety under routine conditions. Based on the principles of non-interventional studies, no directions for treatment were given and all data relating to diagnoses and biochemical measurements were based on reporting from the participating investigators.

Zomacton ${ }^{\circledR} 4 \mathrm{mg}$ (corresponding to 1.3 or $3.3 \mathrm{mg} / \mathrm{mL}$, depending on the preparation) and Zomacton ${ }^{\circledR} 10 \mathrm{mg} / \mathrm{mL}$ were prescribed by the physicians. According to the Zomacton ${ }^{\circledR}$ Summary of Product Characteristics (SmPC), daily injections could be administered subcutaneously or intramuscularly into the upper arm, thigh, abdomen, or buttock. In consultation with their physicians, patients and their parents or legal guardians were free to choose the type of delivery device, i.e. either an NI device (needle injection or needle pen) or an NF device (ZomaJet ${ }^{\circledR}$ ).

Baseline demographics and patient characteristics were obtained immediately before initiation of Zomacton ${ }^{\circledR}$ treatment and included known auxological measurement values, patient and family medical history, and the clinical and paraclinical diagnoses. Follow-up data were collected during check-up visits at 1, 3,6, and 12 months after treatment start and every 6 months thereafter until the end or discontinuation of therapy.

Because sex steroid priming was introduced into the German diagnostic guidelines as a recommendation at the end of 2008 [5], children with GHD were divided into two subgroups, depending on the time at study inclusion: before or after 2009, i.e. before or after the guidelines introduced the recommendation for sex steroid priming.

\section{Patient Cohorts}

The following cohorts were analysed: (1) a safety cohort comprising all patients enrolled in the studies $(n=1,595),(2)$ an auxological outcome cohort comprising only Zomacton ${ }^{\circledR}$ treated GHD or TS patients who were GH treatment-naïve at study entry and had follow-up data for at least 12 months $(n=$ 856 ), and (3) a device cohort that included those Zomacton ${ }^{\circledR}$ treated patients whose exact delivery device was known $(n=$ $658)$. Auxological outcomes were divided into three age groups ( $\leq 5$ years, $>5$ to 10 years, $>10$ years). The near-adult height (NAH) cohort included all GH-treated patients of the auxological outcome cohort who fulfilled the following criteria: chronological age $(\mathrm{CA}) \geq 14$ years for boys and $\geq 12$ years for girls and 
available data on at least one of the following: $\mathrm{HV}<2 \mathrm{~cm} /$ year or bone age $(\mathrm{BA}) \geq 16$ years for boys and $\geq 14$ years for girls $(n=$ 122).

\section{Objectives and Outcome Measures}

The primary study objective was to assess the auxological outcome and safety of long-term Zomacton ${ }^{\circledR}$ treatment in paediatric patients in routine clinical practice and to compare data for NI versus NF administration devices.

Auxological outcomes included HV, the SDS of height $(\mathrm{H}-$ SDS) and HV (HV-SDS) as well as $\Delta \mathrm{H}$-SDS after 12, 24, and 36 months of therapy (calculated as difference in H-SDS between the end of each interval and baseline). Further outcomes included body mass index (BMI) SDS, BA, development of puberty, and serum concentrations of insulin-like growth factor-I (IGF-I).

Height and weight were converted to SDS using the German reference values reported by Kromeyer-Hauschild et al. [7], and $\mathrm{HV}$ values according to Brandt and Reinken [8]. BA readings were performed according to the method of Greulich and Pyle [9]. BA retardation was calculated as BA minus CA. Puberty was assessed using the Tanner Sexual Maturity Scale for boys [10] and girls [11]. Male and female patients exhibiting G1 and B1 stages of physical development, respectively, were classified as prepubertal and those with $\geq \mathrm{G} 2$ and $\geq \mathrm{B} 2$ as pubertal.

$\mathrm{NAH}$ was expressed as a percentage of target height according to Tanner using the mid-parental height formula $\left(\right.$ Height $_{\text {mother }}+$ Height $\left._{\text {father }}\right) / 2+6.5 \mathrm{~cm}$ for boys, or $-6.5 \mathrm{~cm}$ for girls. Furthermore, NAH-SDS and $\triangle \mathrm{NAH}-\mathrm{SDS}$ (height gain) to baseline were calculated.

Safety outcomes included adverse drug reactions (ADRs) and all serious adverse events. Events were classified by MedDRA Preferred Term/System Organ Class (SOC).

\section{Statistical Analysis}

Due to the non-interventional nature of the studies, various data are missing for some patients and therefore cohort sizes vary between specific analyses.

Statistical evaluation mainly employed basic descriptive statistics. For qualitative variables, absolute and percent frequencies were given. Devices were compared to ADR occurrence in contingency tables and were tested for association using the $\chi^{2}$ test or, if the expected frequencies proved too low, Fisher's exact test was applied. Quantitative variables were presented as mean with standard deviation (SD), in certain cases together with the 95\% confidence interval, minimum and maximum values, and quartiles. They were tested for normal distribution using the KolmogorovSmirnov test. In case of significant deviations from normal distribution, two subgroups each were compared using the MannWhitney $\mathrm{U}$ test; otherwise, the independent samples $t$ test was used. To check whether BMI SDS changed over time, comparisons to baseline were performed using the matched pairs $t$ test for GHD and TS patients separately. Repeated measures analysis of variance (ANOVA) was used to check H-SDS and HV-SDS values for significant change over time, with GHD patients and TS patients being analysed separately. In case of global significant effects, linear contrasts were calculated for pairwise comparisons between time points. For the GHD group, sex was additionally included as a possible influencing factor. To evaluate whether age at inclusion or age at pubertal onset in GHD patients changed over the 20-year observation period, linear regression analyses were used.
Statistical tests were performed two-sided at a significance level of $5 \%$. Due to the descriptive nature of the present analysis, no alpha adjustment for multiple testing was applied, and the results were interpreted accordingly. Statistical analyses were undertaken using IBM SPSS Statistics 25 (IBM Corp., Armonk, NY, USA).

\section{Results}

\section{Patient Demographics and Baseline Characteristics}

Overall, 856 patients were included in the auxological outcome cohort. Patient demographics and baseline characteristics are summarised in Table 1.

Most patients (92.3\%) had GHD; the remaining $7.7 \%$ were patients with TS. The proportion of male patients $(66.3 \%)$ was higher than that of females in the GHD group. As expected, all patients with TS were female. The mean age at start of observation was 9.21 years (males, 9.42 years; females, 8.87 years). The study cohort comprised children of all ages from $<1$ year up to nearly 18 years. Children aged $>10$ years made up the largest group (46.1\%). The mean starting dose of Zomacton ${ }^{\circledR}$ was 28.63 $\mu \mathrm{g} / \mathrm{kg} /$ day in patients with GHD and $41.62 \mu \mathrm{g} / \mathrm{kg} /$ day in patients with TS. Dosages increased slightly from study initiation to the visit at 12 months.

Age distribution of GH patients was analysed by inclusion date, i.e. before 2009 (no guideline recommendation for priming; $n=333$ males; $n=150$ females) and after 2009 (priming recommended by the guideline; $n=191$ males; $n=116$ females). Analysis of the pre-2009 data shows two age peaks at treatment initiation. These two age peaks lost their distinct shape after the guideline change (Fig. 1a), particularly in the male group, where the later age peak practically disappeared. Median age of male and female $\mathrm{GH}$ patients was 10.49 and 9.93 years, respectively, before the guideline recommendation for sex steroid priming was introduced. After the guideline was changed, respective median ages dropped significantly to 8.22 years in males (Mann-Whitney U test, $p=0.005$ ) and 8.70 years in females (Mann-Whitney U test, $p=0.001$ ).

The median baseline age of TS patients was 7.86 years. However, more than $20 \%$ of patients were diagnosed after the age of 11 years (Fig. $1 \mathrm{~b}$ ).

Over the 22-year observation period, there was a significant decrease in age at baseline in the overall GHD cohort. Age at study enrolment decreased significantly by 0.105 years per year (linear regression analysis, $p<0.001$; regression equation: $y=10.5-0.11 x$ ) (Fig. 1c). 
Table 1. Patient demographics and baseline characteristics

\begin{tabular}{|c|c|c|}
\hline & GHD $(n=790)$ & TS $(n=66)$ \\
\hline \multicolumn{3}{|l|}{ Sex, $n(\%)$} \\
\hline Female & $266(33.7)$ & $66(100)$ \\
\hline Male & $524(66.3)$ & - \\
\hline \multicolumn{3}{|l|}{ Age, years } \\
\hline Mean (SD) & $9.30(3.44)$ & $8.06(3.74)$ \\
\hline Median (range) & $9.70(0.21$ to 17.78$)$ & $7.86(2.05$ to 15.82$)$ \\
\hline \multicolumn{3}{|l|}{ Age groups } \\
\hline$\leq 5$ years, $n(\%)$ & $110(13.9)$ & $15(22.7)$ \\
\hline$>5$ to 10 years, $n(\%)$ & $308(39.0)$ & $28(42.4)$ \\
\hline$>10$ years, $n(\%)$ & $372(47.1)$ & $23(34.8)$ \\
\hline \multicolumn{3}{|l|}{ Bone age, years } \\
\hline Mean (SD) & $7.55(3.41)$ & $7.64(3.17)$ \\
\hline Median (range) & $8.00(0.09$ to 17.00$)$ & $8.27(2.06$ to 13.25$)$ \\
\hline \multicolumn{3}{|l|}{ Pre-pubertal } \\
\hline Female, \% & 79.1 & 93.9 \\
\hline Male, \% & 86.1 & - \\
\hline \multicolumn{3}{|l|}{ Dose, $\mu \mathrm{g} / \mathrm{kg} /$ day } \\
\hline Start of study [mean (SD)] & $28.63(5.95)$ & $41.62(9.78)$ \\
\hline After 12 months [mean (SD)] & $31.20(5.89)$ & $43.48(7.72)$ \\
\hline \multicolumn{3}{|c|}{ Documented duration of treatment, months } \\
\hline Mean $(\mathrm{SD})$ & $45.4(29.7)$ & $44.2(29.3)$ \\
\hline Median (range) & $38.00(9$ to 215$)$ & $40.0(9$ to 152$)$ \\
\hline \multicolumn{3}{|l|}{ Height SDS } \\
\hline Mean (SD) & $-2.46(0.81)$ & $-2.68(0.98)$ \\
\hline Median (range) & $-2.42(-9.15$ to 0.79$)$ & $-2.64(-5.58$ to 0.07$)$ \\
\hline \multicolumn{3}{|l|}{ Administration device, $n(\%)$} \\
\hline NI & $192(24.3)$ & $11(16.7)$ \\
\hline NF & $419(53.0)$ & $36(54.5)$ \\
\hline Unknown & $148(18.7)$ & $16(24.2)$ \\
\hline Switch & $31(3.9)$ & $3(4.5)$ \\
\hline
\end{tabular}

GHD, growth hormone deficiency; NF, needle-free; NI, needle injection; SD, standard deviation; SDS, SD score; TS, Turner syndrome.

\section{Auxological Outcome}

\section{Height Parameters}

Baseline H-SDS (mean \pm SD) values were $-2.46 \pm$ 0.81 and $-2.68 \pm 0.98$ in GHD and TS patients, respectively. GHD and TS patients exhibited parallel growth, but the H-SDS increment was significantly greater in GHD patients than in TS patients ( $p=0.012$; Fig. $2 \mathrm{a})$. Respective H-SDS values improved to $-1.99 \pm 0.81$ and $-2.28 \pm 1.04$ after 12 months of treatment and to -1.51 \pm 0.80 and $-1.97 \pm 1.12$ after 36 months. There was a significant increase in $\mathrm{H}$-SDS over the first 3 years of treatment (repeated measures ANOVA, $p<0.001$ ).
H-SDS values showed a significant increase at each follow-up time point compared to the previous year (linear contrasts, $p<0.001)$. In the GHD group, no significant influence of sex on the change in H-SDS was noted ( $p=$ $0.127)$.

Mean HV \pm SD baseline values were $4.98 \pm 2.12$ and $5.74 \pm 2.77 \mathrm{~cm} /$ year in GHD and TS patients, respectively. After 12 months of treatment, respective $\mathrm{HV}$ values improved to $8.22 \pm 2.07$ and $7.68 \pm 2.20 \mathrm{~cm} /$ year (Fig. 2b). Mean HV-SDS reflected the development of HV over time, showing a sharp increase during the first 12 months of GH treatment and subsequent decline in both GHD 

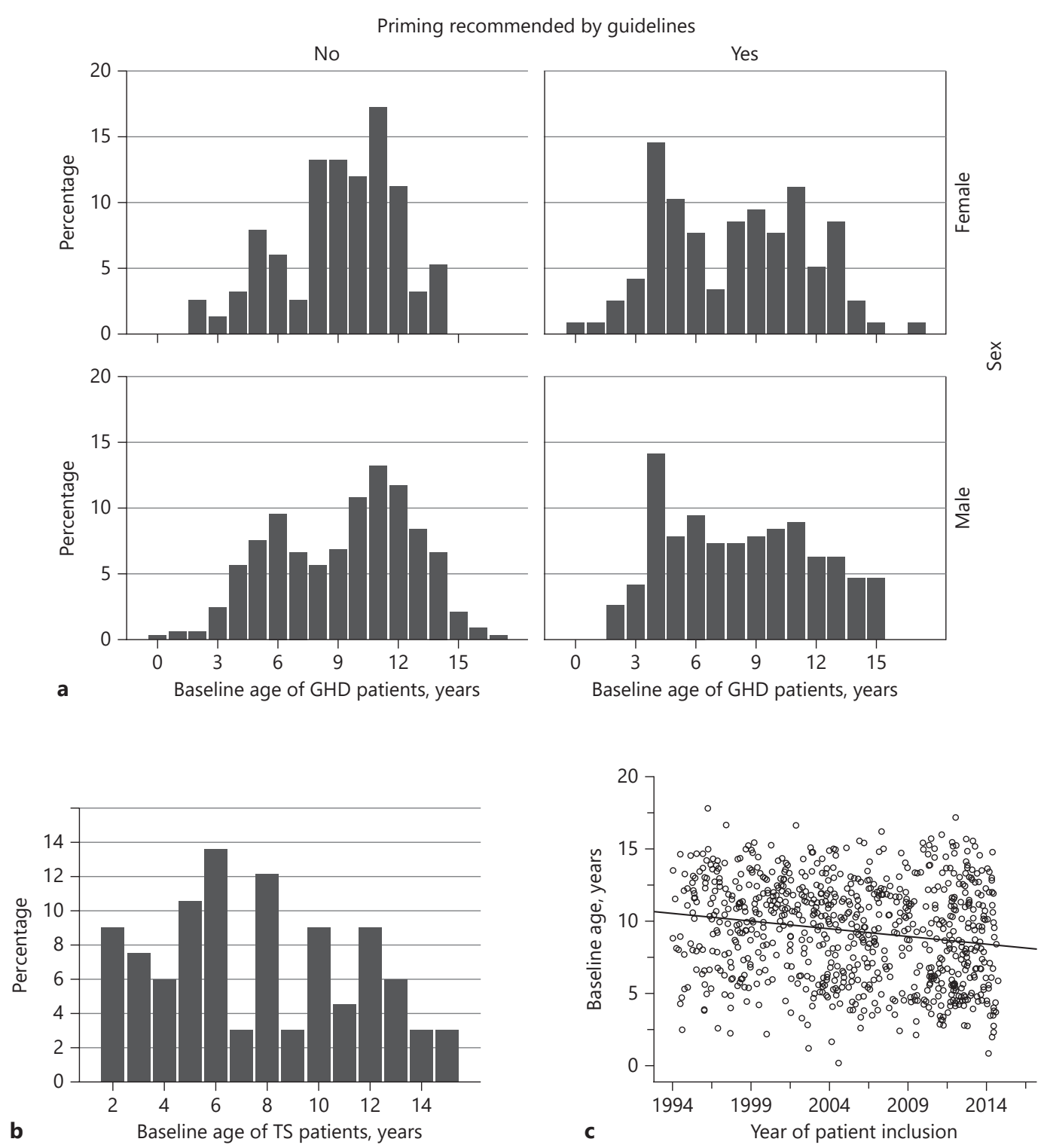

Fig. 1. a Age distribution of patients with growth hormone (GH) deficiency (GHD) starting GH therapy before and after changes in diagnostic guidelines were implemented at the end of 2008. b Age distribution of Turner syndrome (TS) patients starting GH therapy. c Development of chronological age of patients at start of GH therapy.

and TS patients, yet always remaining above $0 \mathrm{HV}$-SDS. HV-SDS exhibited a significant change during the first 3 years of treatment (repeated measures ANOVA, $p<$ 0.001). This effect (change) could be considered strong, with $\eta=0.221$. HV-SDS values showed a significant increase over baseline at 12 months (linear contrasts, $p<$ 0.001), after which time the HV-SDS values decreased again but remained significantly above HV-SDS baseline at all follow-up points $(p<0.001$; Fig. $2 c)$. The GHD group showed no significant sex difference.

Analysis of GHD patients by age group revealed that the greatest treatment effect in terms of $\Delta \mathrm{H}$-SDS (differences in height from baseline, calculated for each treatment interval) occurred in patients aged $\leq 5$ years during the first 
Fig. 2. Mean height standard deviation score (SDS) (a), mean height velocity (HV) (b), and mean HV-SDS (c) during growth hormone $(\mathrm{GH})$ treatment of patients with GH deficiency (GHD) (left) and Turner syndrome (TS) (right) patients. Data are expressed as mean and 95\% confidence interval (CI).
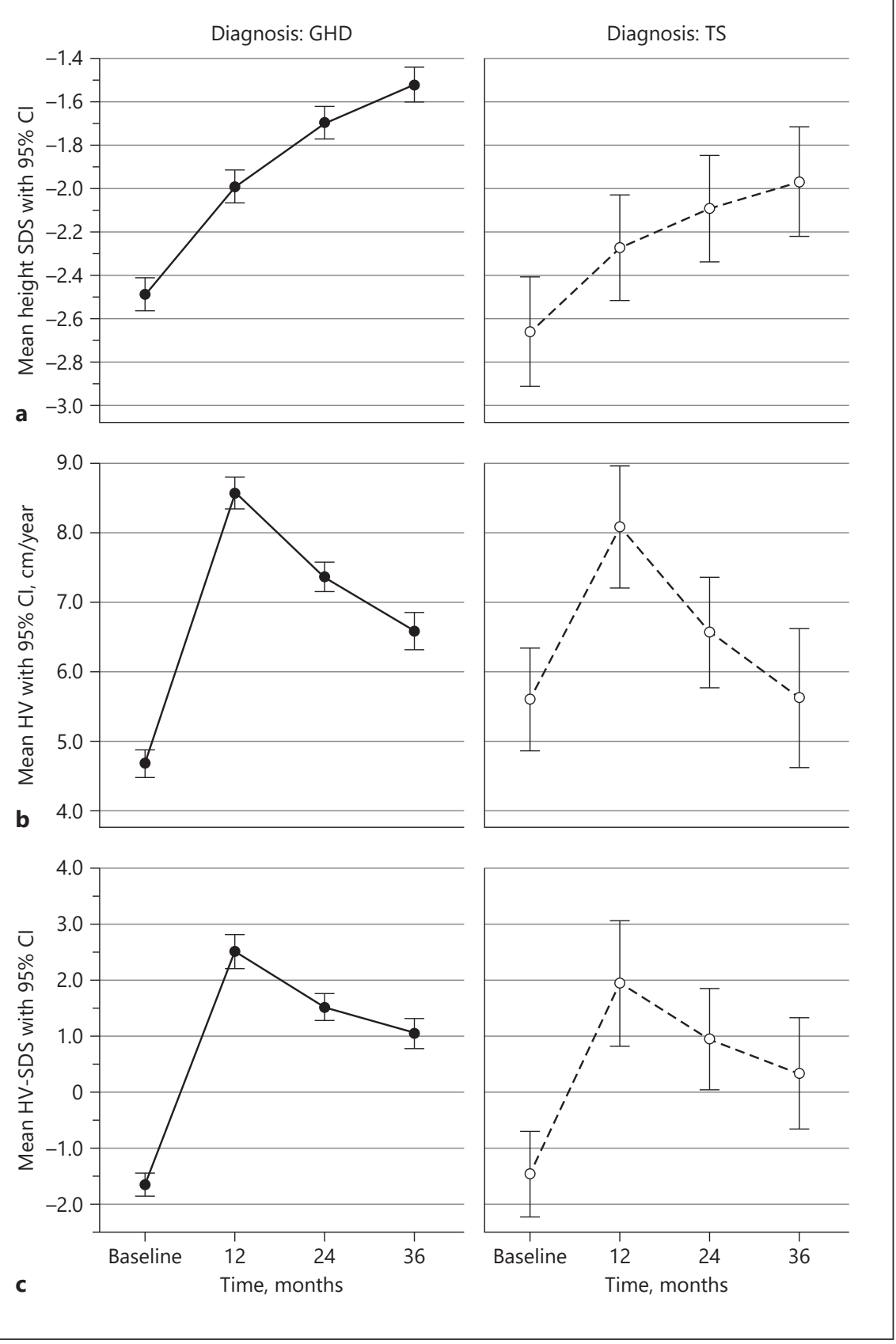

treatment year $(0.66 \Delta \mathrm{H}$-SDS). By contrast, first-year treatment effect was lowest in patients aged $>10$ years $(0.32 \Delta \mathrm{H}$ SDS). During the second and third years of GH treatment, the effect decreased across all age groups (Fig. 3).

\section{Near-Adult Height}

During the observational period, 114 GHD patients met the criteria for NAH, which was a median of -1.3 SDS in males and -1.4 SDS in females, corresponding to 95.9 and $96.9 \%$, respectively, of the median target heights according to Tanner (Table 2). Of the TS patients, 8 patients met the criteria for NAH; however, this subgroup was too small for reliable analysis.

Statistical analyses revealed a significant positive correlation of moderate strength between $\mathrm{NAH}$ and age at $\mathrm{NAH}$ for both male and female GHD patients (Pearson correlation, $R=0.426, p=0.002$ [males]; $R=0.467, p<$ 0.001 [females]); Fig. 4). 
Fig. 3. Gain in mean height standard deviation score $(\Delta \mathrm{H}-\mathrm{SDS})$ during the 1 st, $2 \mathrm{nd}$, and 3rd year of growth hormone treatment of patients with growth hormone deficiency, stratified by age at treatment start.

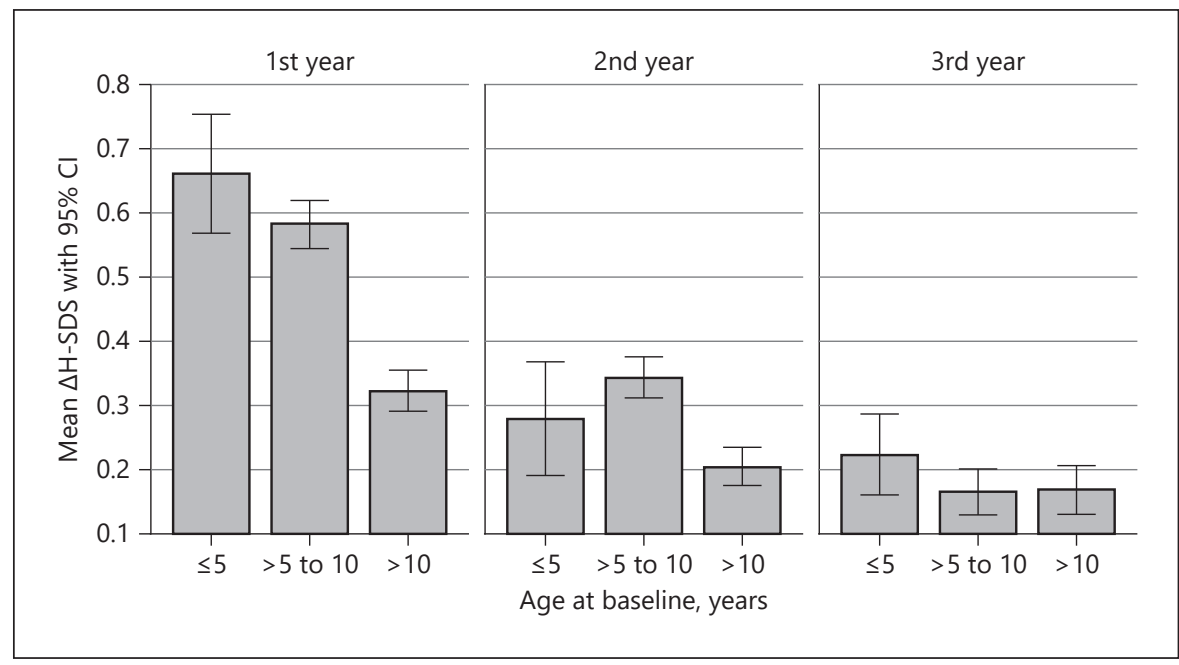

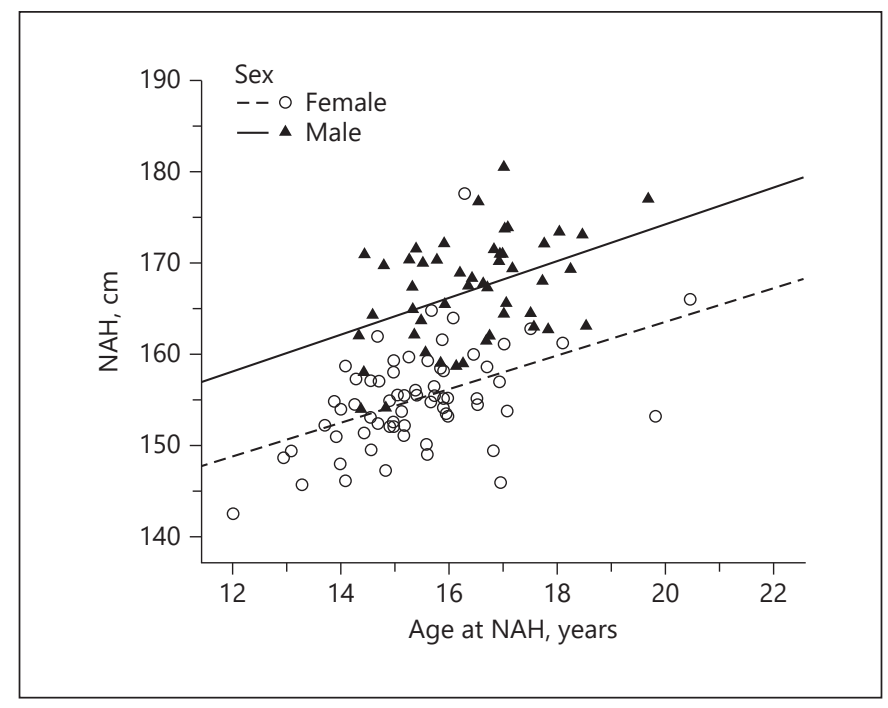

Fig. 4. Near-adult height (NAH) by chronological age of patients with growth hormone deficiency meeting the following criteria: chronological age $\geq 14$ years for boys and $\geq 12$ years for girls and height velocity $<2 \mathrm{~cm} /$ year and/or bone age $\geq 16$ years for boys and $\geq 14$ years for girls.

\section{Body Mass Index}

Before GH therapy, mean BMI SDS in GHD $(-0.39 \pm$ $1.11)$ and TS $(0.01 \pm 0.98)$ patients were comparable to normal children [12]. BMI SDS decreased between treatment start and 12 months in both GHD $(-0.44 \pm 1.10$ SDS; two-sided $t$ test, $p=0.008)$ and TS $(-0.07 \pm 0.93$ SDS, ns) patients. Subsequently, BMI SDS increased again to $-0.30 \pm 1.12$ in GHD patients and $0.38 \pm 0.87$ in TS patients at 36 months but remained within the normal range.

Needle-Free and Needle-Based GH

Therapy in Children

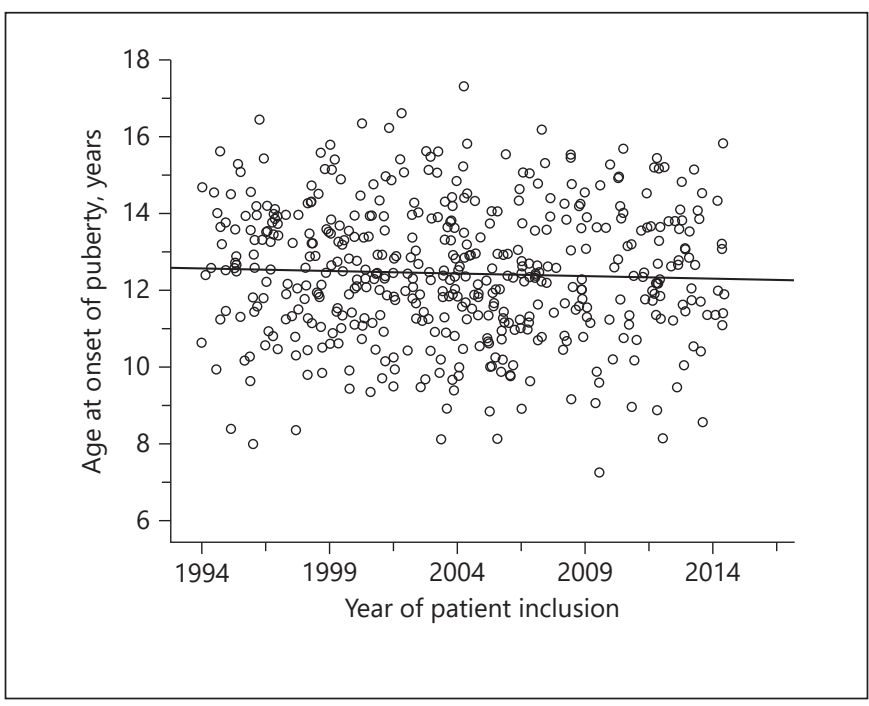

Fig. 5. Development of chronological age at onset of puberty over time.

Bone Age

At the start of GH therapy, BA was delayed relative to $\mathrm{CA}$, with respective mean delays of $2.05 \pm 1.27$ years and $1.53 \pm 1.20$ years being noted in GHD in TS patients. The difference between BA and CA decreased after 12 months of treatment (GHD, $1.58 \pm 1.3$ years; TS, $1.12 \pm 1.42$ years), but BA delay persisted throughout the observation period. 
Fig. 6. Gain in mean height standard deviation score $(\Delta \mathrm{H}-\mathrm{SDS})(\mathbf{a})$ and mean height velocity SDS (HV-SDS) (b) of patients with growth hormone deficiency using needle injection (NI) or needle-free (NF) administration devices. Data are expressed as mean and $95 \%$ confidence interval (CI).
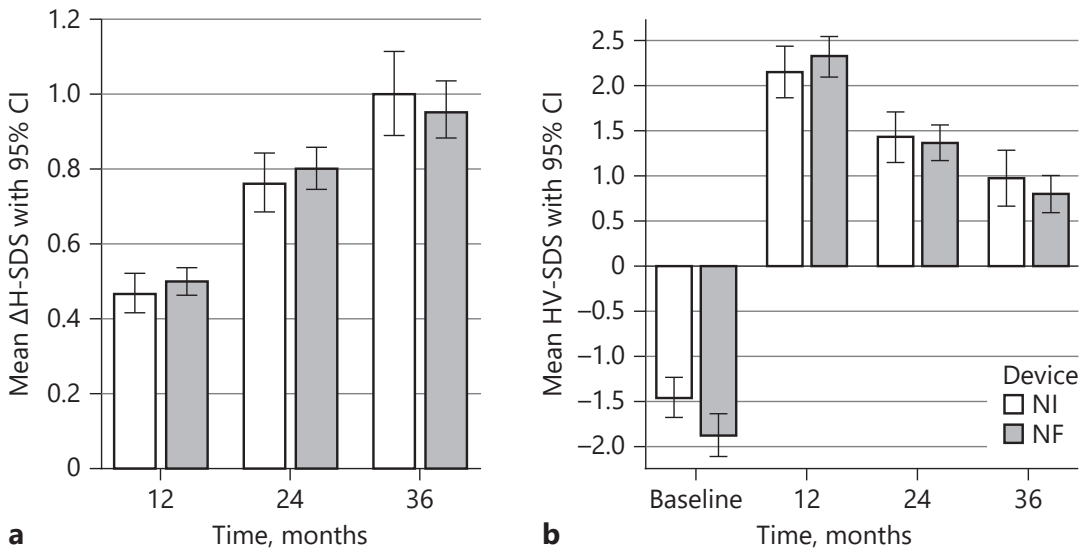

Pubertal Development

Most children were prepubertal, i.e. G1 (boys) and B1 (girls), when they started GH therapy; $86.1 \%$ of boys and $79.1 \%$ of girls with GHD had not yet entered puberty, whereas $93.9 \%$ of TS patients were prepubertal. Over the course of the study, most patients entered puberty; respective mean ages at onset of puberty $(\geq \mathrm{G} 2 / \mathrm{B} 2)$ in boys and girls with GHD were $12.84 \pm 1.78$ and $11.89 \pm 1.46$ years. Mean age at onset of puberty in TS patients was $12.84 \pm 1.72$ years, be it spontaneously or medically induced. Mean age at menarche was $13.8 \pm 1.14$ years and $14.95 \pm 1.41$ years in girls with GHD and TS, respectively.

In the GHD cohort, there was a slightly decreasing trend of 0.013 years per year in age at onset of puberty during the 22-year observational period (linear regression analysis, $p=0.368$; regression equation: $y=12.6-$ $0.01 x$; Fig. 5).

\section{IGF-I Serum Concentrations}

After 12 months of GH treatment, median increase in serum IGF-I concentrations was more than 1.9-fold in GHD patients and more than 1.8 -fold in TS patients. This effect was seen across all three age groups ( $\leq 5$ years, $>5$ to 10 years, and $>10$ years).

\section{NI versus NF Devices}

Choice of delivery device was documented for 658 patients, of whom $69.1 \%$ opted for an NF device while the remaining $30.9 \%$ chose an NI device. Patients opting for NF administration were slightly younger than those opting for NI administration $(8.57 \pm 3.42$ vs. $9.62 \pm 3.34$ years). No difference in choice of device was observed between the sexes.
In GHD patients, growth parameters showed no significant differences between NI and NF administration. Mean $\triangle \mathrm{H}$-SDS and HV-SDS were comparable at all time points (Fig. 6a, b). There were also no significant differences between NI and NF administration regarding NAH and the percentage of target height according to Tanner for both boys and girls (Table 2).

Similarly, analysis of the TS patients' auxological data revealed no significant differences between NF and NI administration. Due to the small number of cases and the ensuing high level of data variability, no figure is shown.

IGF-I serum concentrations, however, exhibited a significant difference between NF and NI administration in GHD patients aged $\leq 5$ years. In this age group, NF administration $(n=42)$ was associated with a 2.5 -fold median increase in IGF-I levels, while the corresponding increase with NI administration was only 1.3 -fold ( $n=15$; Mann-Whitney $\mathrm{U}$ test, $p=0.014)$. No significant differences between administration devices were observed in the other age groups (Fig. 7).

\section{Safety}

Overall, 199 ADRs were reported in 147 (9.2\%) patients of the safety cohort $(n=1,595)$. Among patients with GHD and TS, 8.3 and $8.5 \%$, respectively, experienced ADRs. Most frequently reported $(n \geq 10)$ ADRs by SOC were general disorders and administration site conditions $(n=74)$, nervous system disorders $(n=45)$, and musculoskeletal, connective tissue and bone disorders $(n=22)$. ADRs reported in $\geq 1 \%$ of patients were headache (2.4\%) and haematoma (3.2\%). 
Table 2. Near adult height (NAH) of female and male patients with growth hormone deficiency (GHD) using needle injection (NI) or needle-free (NF) administration devices

\begin{tabular}{|c|c|c|c|c|c|c|c|c|}
\hline \multirow[t]{2}{*}{ Device } & \multirow[t]{2}{*}{$n$} & \multirow[t]{2}{*}{ Mean } & \multirow[t]{2}{*}{ SD } & \multirow[t]{2}{*}{ Min } & \multirow[t]{2}{*}{ Max } & \multicolumn{3}{|c|}{ Percentiles } \\
\hline & & & & & & 25 th & $\begin{array}{l}\text { 50th } \\
\text { (median) }\end{array}$ & 75th \\
\hline \multicolumn{9}{|l|}{ Female } \\
\hline \multicolumn{9}{|l|}{ NI } \\
\hline $\mathrm{NAH}, \mathrm{cm}$ & 24 & 155.3 & 6.2 & 145.7 & 177.6 & 152.6 & 154.3 & 158.4 \\
\hline NAH, $\%$ of Tanner & 24 & 96.3 & 4.9 & 82.5 & 108.8 & 93.9 & 96.5 & 98.6 \\
\hline Height gain, $\mathrm{cm}$ & 24 & 25.2 & 9.3 & 3.2 & 47.4 & 18.9 & 23.9 & 32.5 \\
\hline NAH SDS & 24 & -1.4 & 0.9 & -2.6 & 1.7 & -1.9 & -1.6 & -0.9 \\
\hline Height SDS gain & 24 & 1.0 & 0.4 & -0.2 & 1.7 & 0.7 & 1.1 & 1.3 \\
\hline \multicolumn{9}{|l|}{ NF } \\
\hline $\mathrm{NAH}, \mathrm{cm}$ & 30 & 155.4 & 5.5 & 142.5 & 166.0 & 152.1 & 155.5 & 159.0 \\
\hline NAH (\% of Tanner) & 19 & 96.8 & 3.3 & 87.5 & 100.2 & 95.0 & 97.8 & 99.6 \\
\hline Height gain, $\mathrm{cm}$ & 30 & 31.8 & 18.6 & 8.4 & 87.2 & 17.2 & 27.9 & 36.5 \\
\hline NAH SDS & 30 & -1.4 & 0.6 & -3.2 & -0.1 & -1.8 & -1.4 & -1.0 \\
\hline Height SDS gain & 30 & 1.2 & 0.9 & -0.1 & 4.2 & 0.8 & 1.2 & 1.5 \\
\hline \multicolumn{9}{|l|}{ Total } \\
\hline $\mathrm{NAH}, \mathrm{cm}$ & 54 & 155.4 & 5.8 & 142.5 & 177.6 & 152.4 & 155.0 & 158.6 \\
\hline NAH (\% of Tanner) & 43 & 96.5 & 4.2 & 82.5 & 108.8 & 94.6 & 96.9 & 99.1 \\
\hline Height gain, $\mathrm{cm}$ & 54 & 28.8 & 15.4 & 3.2 & 87.2 & 18.3 & 25.1 & 33.6 \\
\hline NAH SDS & 54 & -1.4 & 0.7 & -3.2 & 1.7 & -1.9 & -1.4 & -1.0 \\
\hline Height SDS gain & 54 & 1.1 & 0.7 & -0.2 & 4.2 & 0.7 & 1.1 & 1.5 \\
\hline \multicolumn{9}{|l|}{ Male } \\
\hline \multicolumn{9}{|l|}{ NI } \\
\hline $\mathrm{NAH}, \mathrm{cm}$ & 14 & 165.4 & 4.9 & 158.7 & 173.4 & 161.1 & 164.0 & 170.2 \\
\hline $\mathrm{NAH}, \%$ of Tanner & 14 & 95.1 & 4.2 & 87.8 & 102.3 & 91.6 & 95.5 & 99.0 \\
\hline Height gain, $\mathrm{cm}$ & 14 & 34.5 & 17.5 & 11.3 & 71.3 & 22.4 & 31.2 & 42.8 \\
\hline NAH SDS & 14 & -1.5 & 0.8 & -2.6 & -0.2 & -2.3 & -1.4 & -1.0 \\
\hline Height SDS gain & 14 & 0.8 & 0.7 & -0.4 & 1.9 & 0.2 & 0.8 & 1.3 \\
\hline \multicolumn{9}{|l|}{$\mathrm{NF}$} \\
\hline $\mathrm{NAH}, \mathrm{cm}$ & 27 & 166.8 & 6.3 & 153.9 & 180.5 & 162.7 & 167.5 & 171.0 \\
\hline NAH, $\%$ of Tanner & 22 & 95.4 & 2.9 & 86.3 & 99.8 & 93.9 & 96.4 & 97.0 \\
\hline Height gain, $\mathrm{cm}$ & 27 & 38.7 & 19.5 & 15.9 & 76.1 & 21.0 & 35.0 & 50.9 \\
\hline NAH SDS & 27 & -1.3 & 0.7 & -2.6 & 0.2 & -1.9 & -1.3 & -0.7 \\
\hline Height SDS gain & 27 & 0.8 & 0.8 & -0.8 & 2.4 & 0.1 & 0.7 & 1.2 \\
\hline \multicolumn{9}{|l|}{ Total } \\
\hline $\mathrm{NAH}, \mathrm{cm}$ & 41 & 166.3 & 5.8 & 153.9 & 180.5 & 162.1 & 167.3 & 170.3 \\
\hline NAH, $\%$ of Tanner & 36 & 95.3 & 3.4 & 86.3 & 102.3 & 92.6 & 95.9 & 97.1 \\
\hline Height gain, $\mathrm{cm}$ & 41 & 37.2 & 18.7 & 11.3 & 76.1 & 21.9 & 33.9 & 47.7 \\
\hline NAH SDS & 41 & -1.4 & 0.7 & -2.6 & 0.2 & -2.0 & -1.3 & -0.8 \\
\hline Height SDS gain & 41 & 0.8 & 0.7 & -0.8 & 2.4 & 0.2 & 0.8 & 1.2 \\
\hline
\end{tabular}

NAH defined as chronological age $\geq 12$ years for girls and $\geq 14$ years for boys and at least one of the following: height velocity $(\mathrm{HV})<2 \mathrm{~cm} /$ year or bone age $\geq 14$ years for girls and $\geq 16$ years for boys. SD, standard deviation; SDS, SD score.

Type 1 diabetes mellitus was reported in 1 patient. There were no reports of tumour development, and no patient died during the study period.

Generally, slightly more ADRs were reported in patients using NF devices (7.8\%) than in those using NI de- vices $(5.3 \%)$ but the difference was not significant. Haematomas were reported significantly more frequently after using an NF device (2\%) compared to an NI device $(0 \%)$ (Fisher's exact test, $p=0.005)$. 
Fig. 7. Changes in IGF-I, expressed as foldincrease after 12 months of growth hormone $(\mathrm{GH})$ therapy, in different age groups of patients with $\mathrm{GH}$ deficiency (GHD; $\mathbf{a}$ ) or Turner syndrome (TS; b) using needle injection (NI) or needle-free (NF) administration devices. Data are expressed as median and range. ${ }^{*} p=0.014$.

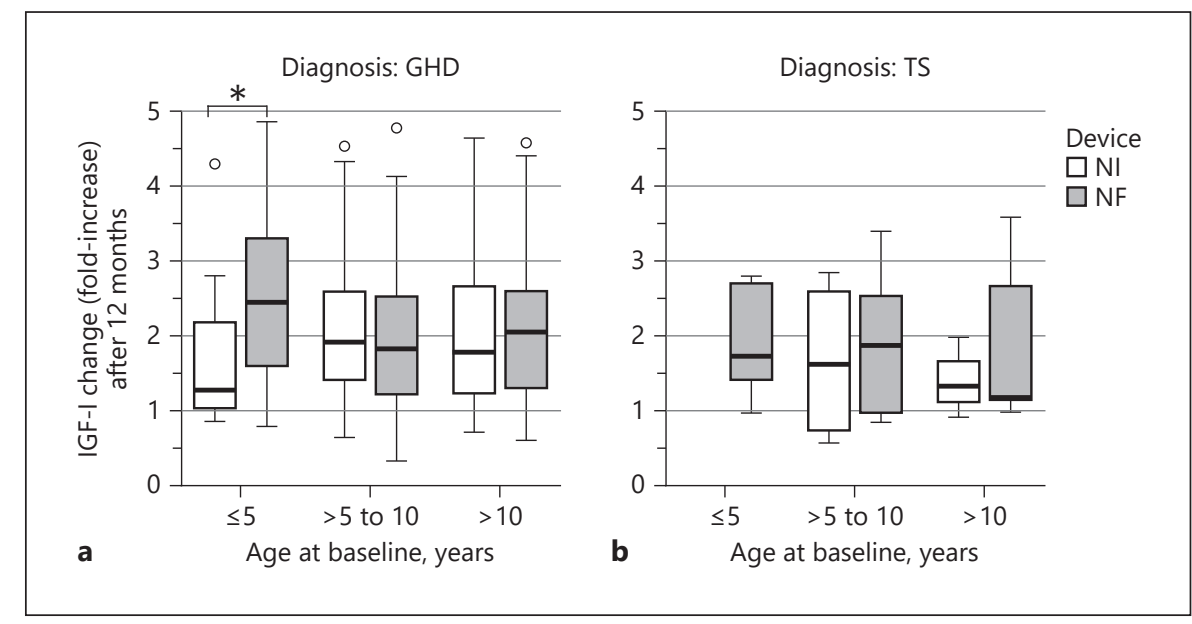

\section{Discussion}

This pooled analysis of three hitherto unpublished, consecutively conducted, prospective, observational studies of Zomacton ${ }^{\circledR}$ (somatropin) in GH treatment-naïve paediatric patients with GHD or TS compared the auxological outcome and safety of NF and NI devices. To our knowledge, this is the largest study of this type to date. Overall, the combined results from the three studies, which were conducted over a 22-year period, show that treatment with Zomacton ${ }^{\circledR}$ improves the auxological outcome in children with GHD or TS. This is in line with previous findings that $\mathrm{GH}$ replacement with Zomacton ${ }^{\circledR}$ normalises linear growth $[13,14]$. Furthermore, treatment with an NF device was found to be non-inferior compared to an NI device.

The first treatment year is crucial, as it is indicative of overall future height gain, not only in children with GHD [15] but also in those with TS [16]. As expected, catch-up growth after start of GH therapy in the present study occurred mainly in the first year of treatment, similarly to other published database studies $[17,18]$. Baseline mean age of our GHD cohort was $9.30 \pm 3.44$ years, with patients aged $>10$ years representing the largest age group (47.1\%). This must be taken into consideration when comparing overall auxological outcomes in our study with other studies, since CA at start of GH therapy is a predictive factor for first-year treatment response [19]. Start of GH therapy after the age of 12 years and/or after the onset of puberty is considered a late start. Published data indicate that growth response to GH treatment is markedly reduced in older children, especially in those with idiopathic GHD [20]. This is in accordance with our data, which show that GH treatment in the first year leads to less improvement in H-SDS in GHD patients aged $>10$ years, i.e. the largest age group in our study, and to the greatest effect in patients aged $\leq 5$ years, who gained 0.66 SDS in height and 4.77 SDS in HV. The growth response is comparable to other studies in prepubertal GHD patients $[17,18,21,22]$.

Thus, the earlier GH is diagnosed and GH treatment is initiated, the better the treatment outcome. Hence, it is encouraging that age at baseline decreased significantly over the 22-year observational period of this study, suggesting that in recent years there has been considerable progress in diagnostic testing for GHD and diagnosing children at an earlier age.

Age at pubertal onset also exhibited a decreasing trend of 0.013 years per year in our GHD cohort, confirming a secular trend over the 22-year observational period. Age at menarche in girls with GHD was $13.8 \pm 1.14$ years, i.e. about 1 year later than in the general population (12.8 years) [23]. Mean age at pubertal onset $(\geq G 2 / B 2)$ was 12.8 years for boys and 11.9 years for girls in our GHD cohort, showing that the onset of puberty was delayed compared to the normal population (11.46 and 9.95 years, respectively) [24]. Therefore, it cannot be precluded that a considerable number of patients, especially in the earlier studies, may have had a CDGP. This is in good agreement with data from the French registry, which also showed that onset of puberty was delayed in patients with idiopathic GHD, with the conclusion that many of these GH-treated patients had CDGP [25].

During the 22-year period of data acquisition, the German diagnostic guidelines for GHD underwent changes, which may have affected the parameters investigated in 
our study. One significant change consisted in the introduction of sex steroid priming in 2008. Generally, GH secretion is low in early puberty, making it difficult sometimes to distinguish between GHD and CDGP [6]. Administration of sex steroids prior to $\mathrm{GH}$ stimulation tests is considered to improve the specificity of diagnosis and reduce false-positive diagnoses. In November 2008, the German diagnostic guidelines introduced the recommendation for sex steroid priming prior to provocative $\mathrm{GH}$ testing in prepubertal boys aged $\geq 10$ years and in prepubertal girls aged $\geq 8$ years [5]. This differs somewhat from the American guidelines, which recommended sex steroid priming in prepubertal boys and girls aged $>11$ and $>10$ years, respectively [26]. To ascertain whether the guideline changes influenced diagnosis, we divided children with GHD into two groups based on study inclusion before or after 2009, i.e. before or after the recommendation for sex steroid priming was introduced. The results suggest that after 2009, the proportion of pubertal children diagnosed with GHD was lower than before 2009. Both girls and boys diagnosed with GHD and included in the study before 2009 were significantly older (median age 10.36 years) than those included after 2009 (8.56 years). This supports the suggestion that before 2009 more children with CDGP may have been misdiagnosed with GHD. Thus, the recommendation to perform sex steroid priming before $\mathrm{GH}$ stimulation may have improved diagnostic accuracy, which is in accordance with several studies showing that priming enhanced diagnostic efficiency [27-29]. As reported previously [25], our data support that the presence of a bias in the auxological data from earlier studies cannot be precluded, since height improvement could also have been due to children with constitutional developmental delay receiving unnecessary GH treatment. Therefore, results of uncontrolled studies and databases must be interpreted critically, especially when untreated control groups are lacking.

It is commonly assumed that NAH is reached when $\mathrm{HV}$ slows to below $2 \mathrm{~cm} /$ year and/or BA has reached 16 years in boys and 14 years in girls [30]. In our analysis, $\mathrm{NAH}$ was considered to have been attained if at least one of the two criteria was fulfilled, and notably, the majority of our patients who met the NAH criteria achieved a final height within the normal range comparable to other longterm studies of GHD [31]. Statistical analysis revealed a moderate, yet significant correlation between NAH $(\mathrm{cm})$ and age at NAH. These results indicate that children with GHD achieve greater NAH if criteria for NAH are met later during adolescence. However, there is considerable

Needle-Free and Needle-Based GH

Therapy in Children inter-individual variability in the growth potential of adolescents, and the decision to stop GH treatment may be premature if based solely on these criteria. It is possible that study patients who met the criteria for NAH at an early age (e.g., girls aged 12 or 13 years) still had growth potential. Therefore, the decision to stop GH treatment should be based on a multifactorial approach.

The TS cohort had a mean age of $8.06 \pm 3.74$ years, with patients aged $>5$ to 10 years representing the largest age group (42.4\%). In TS patients, GH dose and age at treatment initiation are among the most important factors for a successful outcome $[32,33]$. The current therapeutic guidelines for TS patients recommend an early start of GH treatment after the age of 2 years as soon as height falls below the third percentile of the growth chart for healthy females [34]. Our data are in accordance with Simm et al. [35], suggesting that more than $20 \%$ of TS patients are diagnosed only after the age of 11 years. These patients will possibly have missed the opportunity of early GH treatment and the associated prospect of normalising height. In TS patients, pubertal onset occurred at age $12.84 \pm 1.72$ years, and age at menarche was $14.95 \pm 1.41$ years. TS in itself is characterised by gonadal failure due to streak gonads in many patients. Hence, delayed puberty is characteristic of TS patients. However, TS patients often receive oestrogen treatment to induce puberty and prevent delay in pubertal development [36], and therefore, the data are unlikely to represent spontaneous onset of puberty.

The mean starting dose of Zomacton ${ }^{\circledR}$ in patients with TS was $41.62 \mu \mathrm{g} / \mathrm{kg} /$ day. Hence, TS patients were initially dosed lower than the approved dose, which according to the Zomacton ${ }^{\circledR} \mathrm{SmPC}$ is $0.05 \mathrm{mg} / \mathrm{kg}$ body weight for TS. These results show that there is still scope for improvement regarding the diagnosis and treatment of patients with TS. The starting dose of $28.63 \mu \mathrm{g} / \mathrm{kg} /$ day for GHD patients was in the upper range of the recommended dose for GHD, which according to the Zomacton ${ }^{\circledR} \mathrm{SmPC}$ is $0.02-0.03 \mathrm{mg} / \mathrm{kg}$ body weight. Dosages increased slightly from start of study to the visit at 12 months. These values are slightly higher than the-real life doses reported by Blankenstein et al. [37], which are only in the medium $\mathrm{GH}$ dose range.

Several bioequivalence studies have compared the pharmacokinetics and pharmacodynamics of GH administration using NF and NI devices [38, 39], but no other comparative study of similar size has been published so far. The results of our pooled analysis show that NF administration is non-inferior to NI in GHD patients as regards HV-SDS and $\triangle \mathrm{H}$-SDS in the first 3 treatment years 
as well as NAH, and thus are similar to the findings of a small 26-patient study [40].

It is important to note that non-inferiority in our study does not represent equivalence. In the absence of an accepted scientific definition of a clinically relevant difference, clinical equivalence cannot be statistically proven. However, mean $\triangle \mathrm{H}$-SDS and HV-SDS were comparable between NF and NI administration devices at all time points. Regarding the increase in IGF-I serum concentrations at 12 months, however, there was a significant difference between the $\leq 5$ years NF and NI groups of GHD patients, indicating an advantage for the NF device. Therefore, while it was not possible to demonstrate equivalence, this study showed that the use of NF devices was not associated with a worse outcome than the use of NI devices. NF devices are considered to improve patient adherence to treatment [41], and the underlying jet-injection technology has been improved substantially over the last decades. By contrast, although modern needle-based pens may not cause any pain during injection, the psychological factors associated with the use of needles may persist. GHD patients' acceptance of needle-based devices may be low due to pain and needle phobia, leading to non-compliance. Adherence is, however, a central issue in GH therapy as low adherence to treatment has been found to be associated with significantly lower growth rates $[41,42]$. NF devices may increase ease of use for selfinjecting children and thus improve adherence. Furthermore, allowing patients to choose a delivery device themselves has been associated with better treatment adherence [42]. In our study, $69.1 \%$ of patients used an NF device, but no information was collected as to whether devices were chosen by the patient themselves, their parents, or their prescribing physicians, and no adherence data were collected. Future studies should address these important issues when comparing and interpreting the two administration devices.

A strength of our study is that observational studies enable the collection and analysis of safety data from large numbers of patients treated in "real-world" clinical practice settings not usually represented in randomised controlled trials. Our analysis revealed no new safety signals, thus confirming an acceptable safety profile for GH therapy in patients with GHD or TS in clinical practice. Compared with NI, the use of an NF device was associated with a higher reporting of ADRs, particularly haematomas. This is in accordance with reports that jet injection is associated with a higher frequency of local reactions than injection by needle or syringe [43-45]. Although haematomas occurred more frequently with NF devices in our studies, the overall numbers of reported ADRs were very low with both types of devices, and potentially may not reflect the actual clinical situation. Owing to the observational study design, the collection of safety data relied on physician reporting of ADRs. It has been shown, however, that safety information collected during the postmarketing phase is often limited due to underreporting of ADRs [46]. According to Lopez-Gonzalez et al. [47], possible causes of underreporting of ADRs include "ignorance" (the notion that only serious ADRs need to be reported), "insecurity" (regarding the actual drug-relatedness of an ADR) and "complacency" (the notion that only safe drugs receive marketing authorisation). Hence, it is likely that expected and common ADRs such as injection site reactions were subject to underreporting in the analysed data. During the 22-year observation period, no malignancies were reported under GH treatment. This is in line with the Pediatric Endocrine Society Drug and Therapeutics Committee's conclusion that "in children without known risk factors for malignancy, GH therapy can be safely administered without concerns about an increased risk for neoplasia" [48]. With regard to diabetes, only 1 case of type 1 diabetes was reported among the 1,595 patients of the safety cohort during the 22 -year observational period. Based on an estimated national incidence rate of 22.9/100,000 person-years in German children aged 0-14 years [49], no increased risk of developing diabetes type 1 under GH therapy was identified in our study.

Due to the characteristics of observational studies, several limitations may have impacted the results of our analysis. Most importantly, patients were not randomly enrolled and assigned to groups of equal size, and as discussed above in the context of ADR reporting, incomplete documentation of data is not infrequent in observational studies. Furthermore, the study included only a small number of patients with TS, thus limiting the statistical power of the analysis and, consequently, the conclusions that can be drawn from the results. However, while these limitations may impact some study results, the overall conclusions from our analysis are that GH treatment is safe and has improved growth parameters of children with GHD or TS over the last more than two decades and that NF administration devices are non-inferior to NI devices. This is an important factor as it offers patients a broader selection of injection devices with similar efficacies and therefore may improve treatment adherence and subsequent outcome. 


\section{Acknowledgements}

The authors thank all participating investigators and site personnel involved in data acquisition. We acknowledge Ulrike von Hehn (medistat GmbH, Kronshagen, Germany) for excellent data management support and statistical analysis as well as Dr. Maren Klug (KW Medipoint, Bonn, Germany) who provided medical writing services and assistance with manuscript preparation and submission.

\section{Statement of Ethics}

Subjects (or their parents or guardians) have given their written informed consent. The study protocol has been approved by the research institute's committee on human research.

\section{Disclosure Statement}

T.R. Rohrer has received honoraria and funding from Ferring, Pfizer, Novo Nordisk, Ipsen and Merck/Serono. S. Ceplis-Kastner is an employee of Ferring Arzneimittel. N. Jorch has received honoraria and funding from Ferring, Lilly, Pfizer, Novo Nordisk, Ipsen, Merck/Serono, and Novartis/Sandoz/Hexal. H.L. Müller has received honoraria and funding from Ferring, Lilly, Pfizer, Novo
Nordisk, Ipsen Merck/Serono, and Novartis/Sandoz/Hexal. $R$. Pfäffle has received honoraria and funding from Ferring, Lilly, Pfizer, Novo Nordisk, Ipsen Merck/Serono, and Novartis/Sandoz/ Hexal. T. Reinehr has received honoraria and funding from Ferring, Lilly, Pfizer, Novo Nordisk, Ipsen, Merck/Serono, and Novartis/Sandoz/Hexal. A. Richter-Unruh has received honoraria and funding from Ferring, Lilly, NovoNordisk, Ipsen, Merck/Serono, and Kyowa Kirin. C. Weißenbacher has no conflicts of interest to declare. P.-M. Holterhus has received honoraria and funding from Ferring, Lilly, Pfizer, Novo Nordisk, Ipsen, and Merck/Serono.

\section{Funding Sources}

The observational studies were sponsored by Ferring Arzneimittel $\mathrm{GmbH}$. Data management, statistics, and medical writing were funded by Ferring Arzneimittel GmbH.

\section{Author Contributions}

S. Ceplis-Kastner designed and directed the project. T.R. Rohrer and P.-M. Holterhus took the lead in preparing the draft manuscript with medical writing assistance. All other authors contributed to data collection, participated in data analysis and interpretation, and critically reviewed the draft manuscript.

\section{References}

1 Pfäffle R. Hormone replacement therapy in children: the use of growth hormone and IGF-I. Best Pract Res Clin Endocrinol Metab. 2015 Jun;29(3):339-52.

2 Reiter EO, Price DA, Wilton P, AlbertssonWikland K, Ranke MB. Effect of growth hormone $(\mathrm{GH})$ treatment on the near-final height of 1258 patients with idiopathic GH deficiency: analysis of a large international database. J Clin Endocrinol Metab. 2006 Jun; 91(6):2047-54

3 Critical evaluation of the safety of recombinant human growth hormone administration: statement from the Growth Hormone Research Society. J Clin Endocrinol Metab. 2001 May;86(5):1868-70.

4 Spoudeas HA, Bajaj P, Sommerford N. Maintaining persistence and adherence with subcutaneous growth-hormone therapy in children: comparing jet-delivery and needlebased devices. Patient Prefer Adherence. 2014 Sep;8:1255-63.

5 Deutsche Gesellschaft für Kinderendokrinologie und -diabetologie. Diagnostik des Wachstumshormonmangels im Kindes- und Jugendalter [Internet] [cited 2018 Oct 11]. Available from: https://www.awmf.org/leitlinien/detail/ll/174-002.html
6 Wetterau LA. The pros and cons of sex steroid priming in growth hormone stimulation testing. J Pediatr Endocrinol Metab. 2012;25(1112):1049-55

7 Kromeyer-Hauschild K, Wabitsch M, Kunze D, Geller F, Geiß HC, Hesse V, et al. Perzentile für den Body-mass-Index für das Kindes- und Jugendalter unter Heranziehung verschiedener deutscher Stichproben. Monatsschr Kinderheilkd. 2001;149(8):807-18.

8 Brandt I, Reinken L. Die Wachstumsgeschwindigkeit gesunder Kinder in den ersten 16 Lebensjahren: longitudinale Entwicklungsstudie Bonn-Dortmund. Klin Padiatr. 1988 Nov-Dec;200(6):451-6.

9 Greulich WW, Pyle SI. Radiographic atlas of skeletal development of the hand and wrist. Stanford: Stanford University Press; 1959. https://doi.org/10.1097/00000441195909000-00030.

10 Marshall WA, Tanner JM. Variations in the pattern of pubertal changes in boys. Arch Dis Child. 1970 Feb;45(239):13-23.

11 Marshall WA, Tanner JM. Variations in pattern of pubertal changes in girls. Arch Dis Child. 1969 Jun;44(235):291-303.

12 WHO Multicentre Growth Reference Study Group. WHO Child Growth Standards based on length/height, weight and age. Acta Paediatr Suppl. 2006 Apr;450:76-85.
13 Zadik Z, Chalew S, Zung A, Landau H, Leiberman E, Koren R, et al. Effect of long-term growth hormone therapy on bone age and pubertal maturation in boys with and without classic growth hormone deficiency. J Pediatr. 1994 Aug; 125(2):189-95.

14 Zadik Z, Zung A, Sarel R, Cooper M. Growth of short children during and after discontinuation of growth hormone therapy. J Clin Endocrinol Metab. 1996 Oct;81(10):3668-70.

15 de Ridder MA, Stijnen T, Hokken-Koelega AC. Prediction of adult height in growth-hormone-treated children with growth hormone deficiency. J Clin Endocrinol Metab. 2007 Mar;92(3):925-31.

16 Ranke MB, Partsch CJ, Lindberg A, Dorr HG, Bettendorf M, Hauffa BP, et al. Adult height after GH therapy in 188 Ullrich-Turner syndrome patients: results of the German IGLU Follow-up Study 2001. Eur J Endocrinol. 2002 Nov; 147(5):625-33.

17 Ranke MB, Lindberg A; KIGS International Board. Observed and predicted growth responses in prepubertal children with growth disorders: guidance of growth hormone treatment by empirical variables. J Clin Endocrinol Metab. 2010 Mar;95(3):1229-37. 
18 Pfäffle R, Land C, Schönau E, Holterhus PM, Ross JL, Piras de Oliveira C, et al. Growth Hormone Treatment for Short Stature in the USA, Germany and France: 15 Years of Surveillance in the Genetics and Neuroendocrinology of Short-Stature International Study (GeNeSIS). Horm Res Paediatr. 2018;90(3): $169-80$.

19 Ranke MB, Lindberg A, Cowell CT, Wikland KA, Reiter EO, Wilton P, et al.; KIGS International Board. Prediction of response to growth hormone treatment in short children born small for gestational age: analysis of data from KIGS (Pharmacia International Growth Database). J Clin Endocrinol Metab. 2003 Jan; 88(1):125-31.

20 Dörr HG, Bettendorf M, Binder G, Dötsch J, Hauffa BP, Mohnike K, et al. Effekte eines späten Beginns einer Therapie mit Wachstumshormon. Monatsschr Kinderheilkd. 2018;166(4):317-24.

21 Bang P, Bjerknes R, Dahlgren J, Dunkel L, Gustafsson J, Juul A, et al. A comparison of different definitions of growth response in short prepubertal children treated with growth hormone. Horm Res Paediatr. 2011; 75(5):335-45.

22 Straetemans S, Thomas M, Craen M, Rooman R, De Schepper J; BESPEED. Poor growth response during the first year of growth hormone treatment in short prepubertal children with growth hormone deficiency and born small for gestational age: a comparison of different criteria. Int J Pediatr Endocrinol. 2018; 2018(1):9.

23 Kahl H, Schaffrath Rosario A, Schlaud M. SchaffrathRosario A, Schlaud M: [Sexual maturation of children and adolescents in Germany. Results of the German Health Interview and Examination Survey for Children and Adolescents (KiGGS)]. 2007;50(5-6): 677-85.

24 Wohlfahrt-Veje C, Mouritsen A, Hagen CP, Tinggaard J, Mieritz MG, Boas M, et al. Pubertal onset in boys and girls is influenced by pubertal timing of both parents. J Clin Endocrinol Metab. 2016 Jul;101(7):2667-74.

25 Carel JC, Ecosse E, Nicolino M, Tauber M, Leger J, Cabrol S, et al. Adult height after long term treatment with recombinant growth hormone for idiopathic isolated growth hormone deficiency: observational follow up study of the French population based registry. BMJ. 2002 Jul;325(7355):70.

26 Grimberg A, DiVall SA, Polychronakos C, Allen DB, Cohen LE, Quintos JB, et al.; Drug and Therapeutics Committee and Ethics Committee of the Pediatric Endocrine Society. Guidelines for growth hormone and insulinlike growth factor-I treatment in children and adolescents: growth hormone deficiency, idiopathic short stature, and primary insulinlike growth factor-I deficiency. Horm Res Paediatr. 2016;86(6):361-97.

27 Martínez AS, Domené HM, Ropelato MG, Jasper HG, Pennisi PA, Escobar ME, et al. Es- trogen priming effect on growth hormone $(\mathrm{GH})$ provocative test: a useful tool for the diagnosis of GH deficiency. J Clin Endocrinol Metab. 2000 Nov;85(11):4168-72.

28 Müller G, Keller A, Reich A, Hoepffner W, Kratzsch J, Buckler JM, et al. Priming with testosterone enhances stimulated growth hormone secretion in boys with delayed puberty. J Pediatr Endocrinol Metab. 2004 Jan;17(1): 77-83.

29 Molina S, Paoli M, Camacho N, Arata-Bellabarba G, Lanes R. Is testosterone and estrogen priming prior to clonidine useful in the evaluation of the growth hormone status of short peripubertal children? J Pediatr Endocrinol Metab. 2008 Mar;21(3):257-66.

30 Ranke MB, Lindberg A, Mullis PE, Geffner ME, Tanaka T, Cutfield WS, et al. Towards optimal treatment with growth hormone in short children and adolescents: evidence and theses. Horm Res Paediatr. 2013;79(2):51-67.

31 Rohayem J, Drechsel H, Tittel B, Hahn G, Pfaeffle R, Huebner A. Long-term outcomes, genetics, and pituitary morphology in patients with isolated growth hormone deficiency and multiple pituitary hormone deficiencies: A single-centre experience of four decades of growth hormone replacement. Horm Res Paediatr. 2016;86(2):106-16.

32 Schweizer R, Ranke MB, Binder G, Herdach F, Zapadlo M, Grauer ML, et al. Experience with growth hormone therapy in Turner syndrome in a single centre: low total height gain, no further gains after puberty onset and unchanged body proportions. Horm Res. 2000; 53(5):228-38

33 Bettendorf M, Inta IM, Doerr HG, Hauffa BP, Mehls O, Ranke MB. Height gain in UllrichTurner syndrome after early and late growth hormone treatment start: results from a large retrospective German study and potential basis for an individualized treatment approach. Horm Res Paediatr. 2013;80(5):356-62.

34 Bondy CA; Turner Syndrome Study Group. Care of girls and women with Turner syndrome: a guideline of the Turner Syndrome Study Group. J Clin Endocrinol Metab. 2007 Jan;92(1):10-25.

35 Simm D, Degenhardt K, Gerdemann C, Völkl TM, Rauch A, Dörr HG. [Chronological age of patients with Turner syndrome at diagnosis]. Klin Padiatr. 2008 Jan-Feb;220(1):16-20.

36 Saenger P, Wikland KA, Conway GS, Davenport M, Gravholt CH, Hintz R, et al.; Fifth International Symposium on Turner Syndrome. Recommendations for the diagnosis and management of Turner syndrome. J Clin Endocrinol Metab. 2001 Jul;86(7):3061-9.

37 Blankenstein O, Snajderova M, Blair J, Pournara E, Pedersen BT, Petit IO. Real-life GH dosing patterns in children with GHD, TS or born SGA: a report from the NordiNet ${ }^{\circledR}$ International Outcome Study. Eur J Endocrinol. 2017 Aug;177(2):145-55.

38 Agersø H, Møller-Pedersen J, Cappi S, Thomann P, Jesussek B, Senderovitz T. Pharmaco- kinetics and pharmacodynamics of a new formulation of recombinant human growth hormone administered by ZomaJet 2 Vision, a new needle-free device, compared to subcutaneous administration using a conventional syringe. J Clin Pharmacol. 2002 Nov;42(11): 1262-8.

39 Brearley C, Priestley A, Leighton-Scott J, Christen M. Pharmacokinetics of recombinant human growth hormone administered by cool.click 2, a new needle-free device, compared with subcutaneous administration using a conventional syringe and needle. BMC Clin Pharmacol. 2007 Oct;7(1):10.

40 Igarashi Y. Clinical evaluation of the needlefree injection system VISION $\left({ }^{\circledR}\right)$ for growth hormone therapy in children. Clin Pediatr Endocrinol. 2006;15(3):117-22.

41 Desrosiers P, O’Brien F, Blethen S. Patient outcomes in the GHMonitor: the effect of delivery device on compliance and growth. Pediatr Endocrinol Rev. 2005 Feb;2 Suppl 3: 327-31.

42 Kapoor RR, Burke SA, Sparrow SE, Hughes IA, Dunger DB, Ong KK, et al. Monitoring of concordance in growth hormone therapy. Arch Dis Child. 2008 Feb;93(2):147-8.

43 McAllister L, Anderson J, Werth K, Cho I, Copeland K, Le Cam Bouveret N, et al. Needle-free jet injection for administration of influenza vaccine: a randomised non-inferiority trial. Lancet. 2014 Aug;384(9944):674-81.

44 Simon JK, Carter M, Pasetti MF, Sztein MB, Kotloff KL, Weniger BG, et al. Safety, tolerability, and immunogenicity of inactivated trivalent seasonal influenza vaccine administered with a needle-free disposable-syringe jet injector. Vaccine. 2011 Nov;29(51):954450.

45 Jackson LA, Austin G, Chen RT, Stout R, DeStefano F, Gorse GJ, et al.; Vaccine Safety Datalink Study Group. Safety and immunogenicity of varying dosages of trivalent inactivated influenza vaccine administered by needle-free jet injectors. Vaccine. 2001 Sep; 19(32):4703-9.

46 Hazell L, Shakir SA. Under-reporting of adverse drug reactions : a systematic review. Drug Saf. 2006;29(5):385-96.

47 Lopez-Gonzalez E, Herdeiro MT, Figueiras A. Determinants of under-reporting of adverse drug reactions: a systematic review. Drug Saf. 2009;32(1):19-31.

48 Raman S, Grimberg A, Waguespack SG, Miller BS, Sklar CA, Meacham LR, et al. Risk of neoplasia in pediatric patients receiving growth hormone therapy-a report from the Pediatric Endocrine Society Drug and Therapeutics Committee. J Clin Endocrinol Metab. 2015 Jun;100(6):2192-203.

49 Bendas A, Rothe U, Kiess W, Kapellen TM, Stange T, Manuwald U, et al. Trends in incidence rates during 1999-2008 and prevalence in 2008 of childhood type 1 diabetes mellitus in Germany-model-based national estimates. PLoS One. 2015 Jul;10(7):e0132716. 